\title{
Primary oral myiasis: A clinical presentation in cerebral palsy
}

\author{
Abdul Ahad G Khan, Kanchan Milind Shah
}

\begin{abstract}
Introduction: Myiasis is the infestation of live human and vertebrate animal with dipterous larvae which feed on the host's dead or living tissue. The most common anatomic sites for myiasis are the nose, eye, lung, ear, anus, vagina and more rarely, the mouth. Incidence of oral myiasis as compared to that of cutaneous myiasis is less as the oral tissues are not permanently exposed to the external environment. Case Report: A case of oral myiasis in the anterior maxillary region in a 12year-old male with mental retardation and cerebral palsy caused by the larvae (maggots) of Musca Nebulo (Family Diptera) (common housefly) is reported. The treatment consisted of manual removal of the larvae by topical application of turpentine oil (used for medicinal purpose) and surgical debridement of the oral wound. Conclusion: Preliminary measures taken to maintain good oral and general hygiene can prevent as well as treat myiasis.
\end{abstract}

Keywords: Oral myiasis, Cerebral palsy, Common house fly, Maggots

Abdul Ahad G Khan ${ }^{1}$, Kanchan Milind Shah ${ }^{1}$

Affiliations: ${ }^{1}$ Department of Oral and Maxillofacial Surgery, Government Dental College and Hospital, Aurangabad, Maharashtra, India.

Corresponding Author: Dr. Abdul Ahad G. Khan, Plot No. A-1, Gut No 13, Opposite Amber Gas Godown, Nasik Road, Padegaon, Aurangabad, Maharashtra, India 431002; Ph: 9552002731, 9324107926; Email: drabdulahadkhan@gmail.com,

drabdulahadkhan09@rediff.com

Received: 12 January 2012

Accepted: 30 March 2012

Published: 01 Febuary 2013
Khan AAG, Shah KM. Primary oral myiasis: A clinical presentation in cerebral palsy. International Journal of Case Reports and Images 2013;4(2):95-98.

$* * * * * * * * *$

doi:10.5348/ijcri-2013-02-269-CR-3

\section{INTRODUCTION}

The term myiasis is derived from Latin word 'muia' which means 'fly' and 'iasis' means 'disease'. It is a pathology caused in human and animal tissue by the larvae that evolve to a parasite. The term was coined by Hope in 1840 [1]. Myiasis was defined by Zumpt as the infestation of live human and vertebrate animals by dipterous larva, which at least for a certain period feed on host's dead or living tissue, liquid body substances or ingested food [2]. Myiasis frequently occurs in rural areas infecting livestock and pets such as dogs and cats. In humans, myiasis prevails in unhealthy individuals frequently found in undeveloped and tropical countries.

Myiasis can be classified clinically as primary (larvae feed on the living tissue) or secondary (larvae feed on dead tissue) [3]. Myiasis can also be classified depending on the condition of the involved tissue into accidental myiasis (larvae ingested along with food), semi-specific (larvae laid on necrotic tissue in wounds) and obligatory myiasis (larvae affecting the undamaged skin) [4]. Further classification can be based on the site as cutaneous, external orifice, internal organs and generalized [5].

The most common anatomic sites for myiasis are the nose, eye, lung, ear, anus, vagina and more rarely, the mouth [6]. Incidence of oral myiasis is less as compared to cutaneous myiasis, as the oral tissues are not permanently exposed to the external environment [7].

Oral myiasis was first described by Laurence in 1909 [8]. Conditions leading to persistent mouth opening 
along with poor hygiene, suppurative lesions, severe halitosis and facial trauma may predispose the patient to oral myiasis [9]. It has been reported among epilepsy patients with lacerated lips following a seizure, incompetent lips and thumb sucking habits [10], advanced periodontal disease [11], at tooth extraction sites [12], fungating carcinoma of buccal mucosa [5] and patient with tetanus with mouth propped open to maintain his airway [13] .

Mouth breathing during sleep, cerebral palsy, alcoholism, mental handicap and hemiplegia may facilitate the development of myiasis. Other contributing factors are poor public and personal hygiene [14].

\section{CASE REPORT}

A 12-year-old male was referred to our department with a complaint of pain, fever and diffuse swelling over the upper lip, predominantly on the right side extending up to the lower eyelid causing inability to open the eye. He had a history of exfoliation of upper anterior teeth secondary to fall about one month back. Medical history revealed severe mental retardation with cerebral palsy. He had a habit of mouth breathing. Severe halitosis was also present.

On local examination the swelling was firm, tender and seemed to be of inflammatory origin. Lips were incompetent. Gingival inflammation was generalized but more severe in the anterior maxillary region having progressed to periodontitis. General as well as oral hygiene was very poor. Maxillary right central and lateral incisors were missing but their sockets were bare and not in the healing phase (Figure 1). White worm like creatures were moving in and around the empty sockets, the gingiva of the maxillary left central incisor and the vestibular area labial to the maxillary incisors (Figures 1,2) that lead to a provisional diagnosis of oral myiasis.

Our line of management began with parenteral hydration, administration of antibiotics (augmentin + metronidazole), vitamin supplements and manual removal of maggots by means of tweezers and oil of turpentine that was done for three consecutive days. Approximately, 30-35 maggots were removed (Figure 3) during each of the two days from the wound, due to which the local condition of the tissue improved progressively. The use of ivermectin [3] was not needed for therapy as local debridement of tissue after removal of the maggots resulted in uneventful healing (Figure 4).

\section{DISCUSSION}

Musca Nebulo is the most common Indian housefly. They are seen in abundance in human dwellings and are very active during summer and rainy season [15]. The life cycle of a fly begins with egg stage followed by the larvae, pupa and finally the adult fly. The conditions required for egg laying and survival of the larvae are

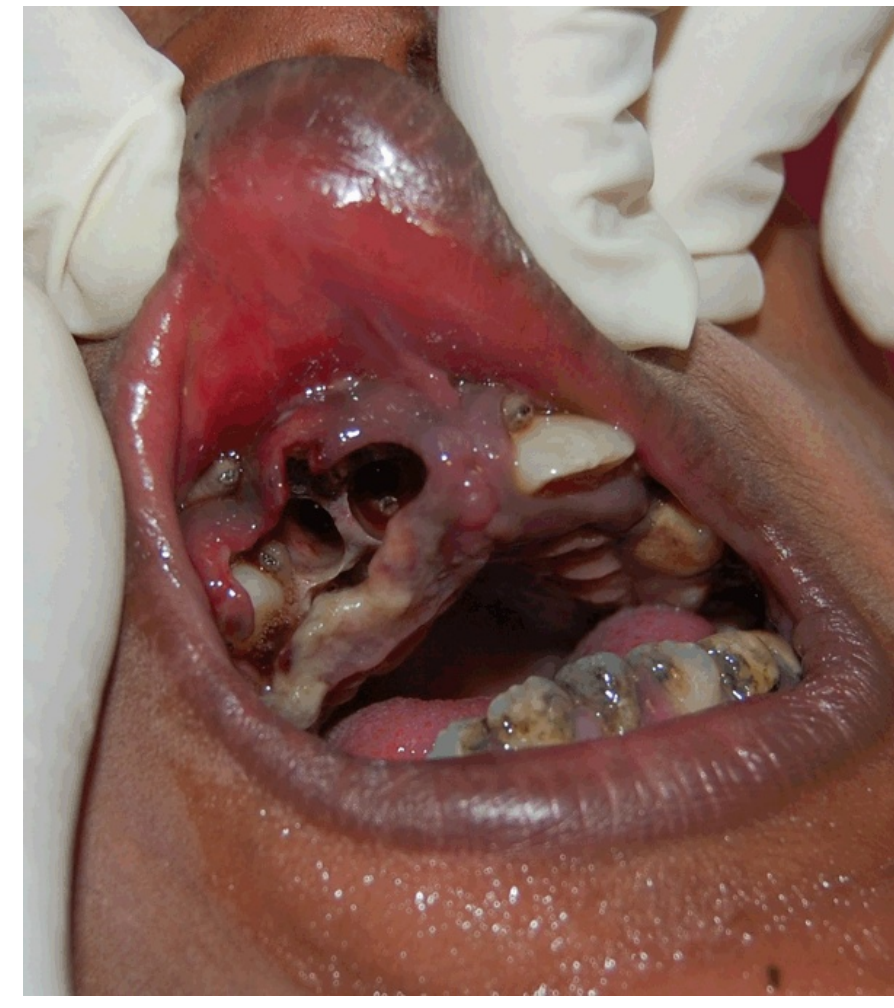

Figure 1: Pretreatment photograph depicting the maggots moving around the wound.

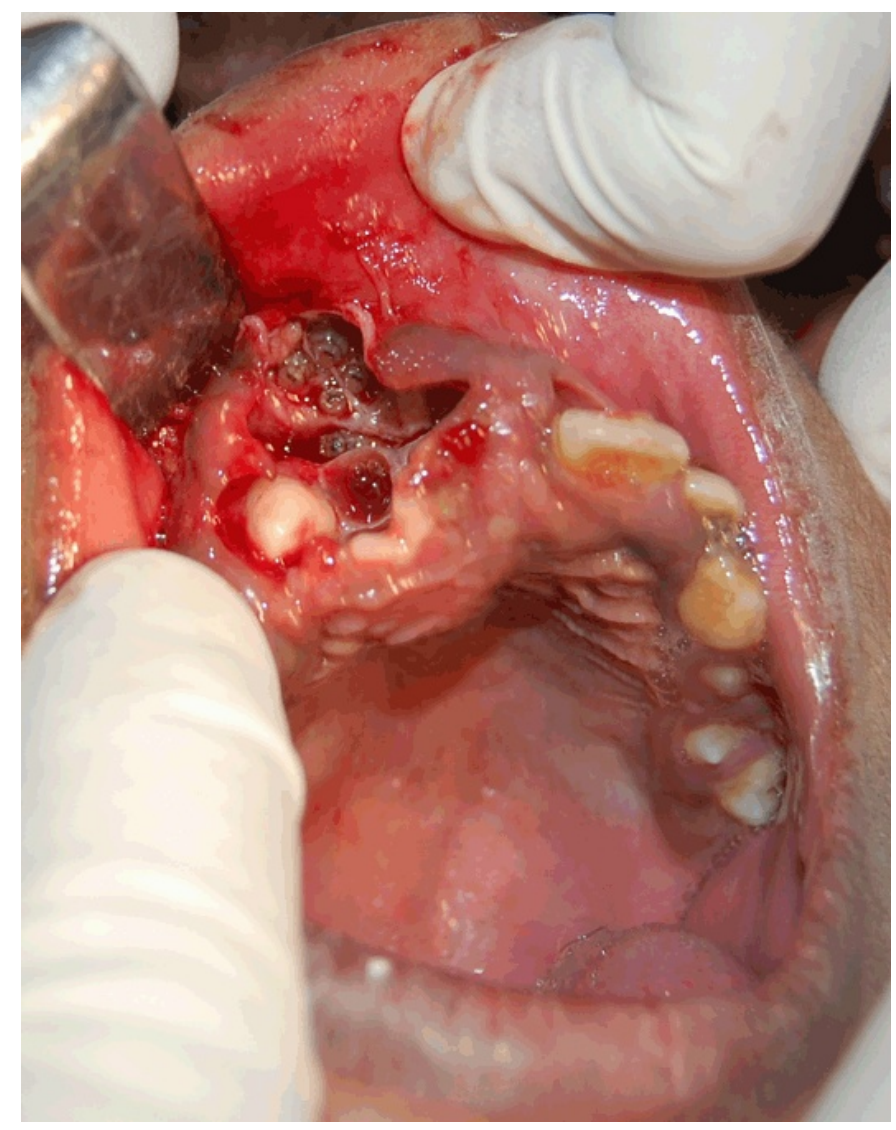

Figure 2: Pretreatment photograph depicting the maggots deeply embedded in the wound. 


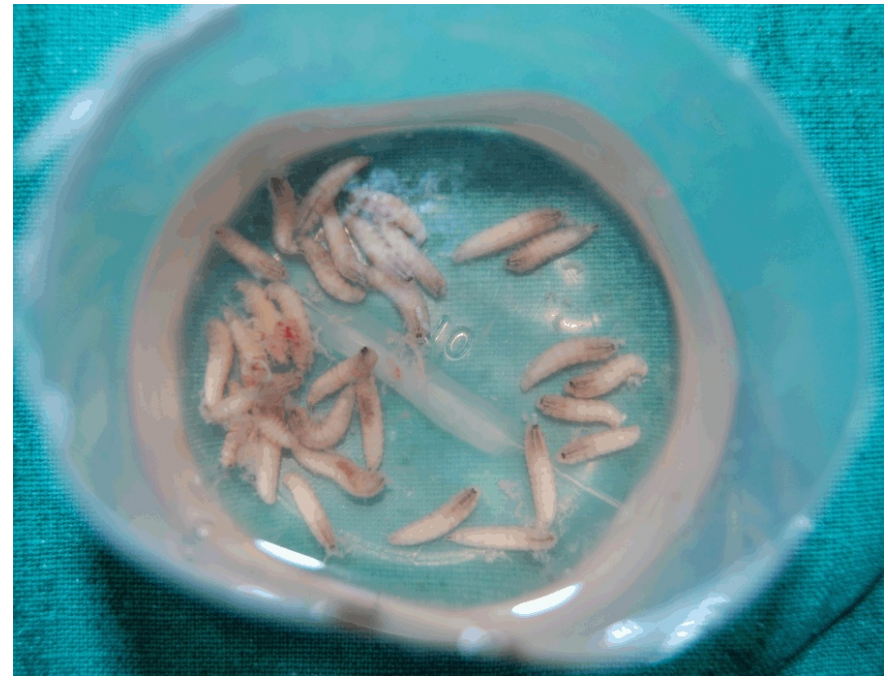

Figure 3: Removed maggots in a single sitting for two consecutive days.

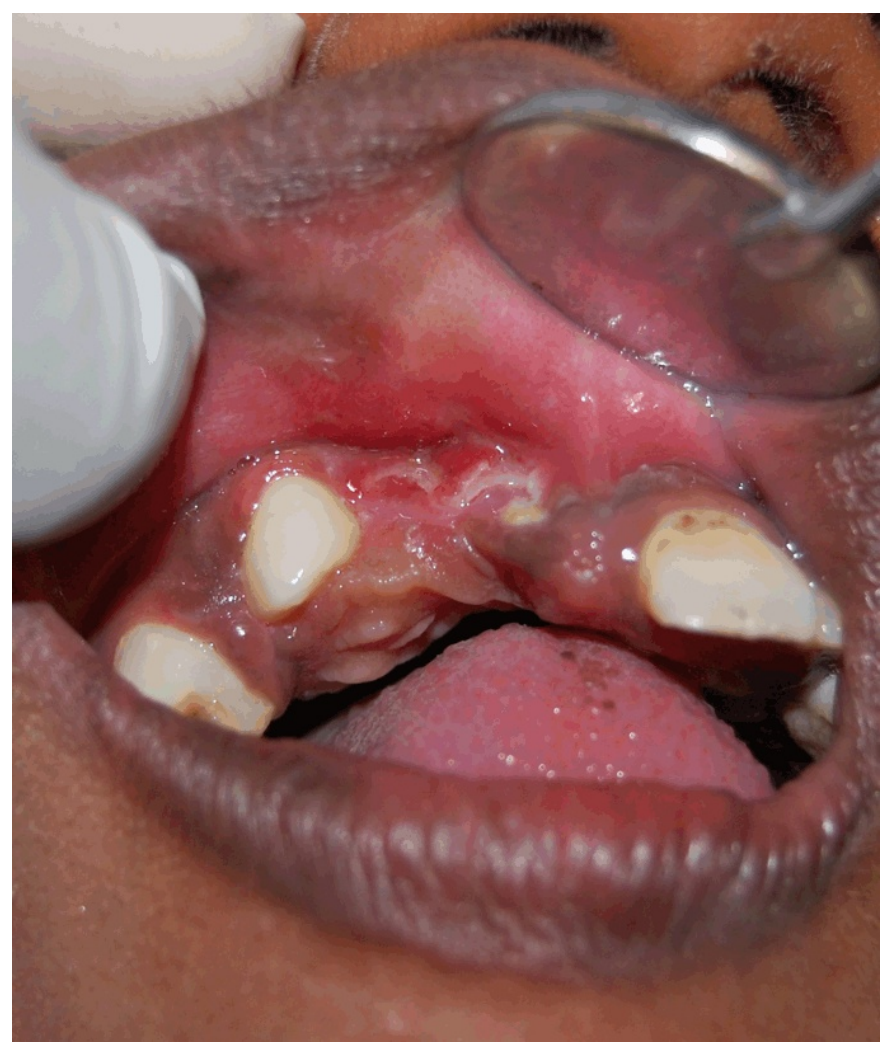

Figure 4: Healed wound after complete removal of maggots.

moisture, necrotic tissue and suitable temperature. Thus, wounds, open sores, scabs, ulcers contaminated with discharges facilitate the same. The developmental transition via the larval stage requires an intermediate host. In our case an empty socket and existing periodontitis contributed to the mechanical support and suitable substrate and temperature for the survival of the larvae. The stage of larvae lasts for six to eight days during which they are parasitic to human beings. The larvae have backward directed segmental hooks with which they anchor themselves to the surrounding tissue. They are photophobic and tend to hide deep into the tissues for a suitable niche to develop into pupa [15]. The present case also showed the larvae burrowed deep inside the socket (Figure 2). Manual removal of larvae from the host is difficult due to presence of these hooks. So, when multiple maggots are detected, as observed in our case, elimination can be achieved with agents like turpentine oil or topical irritants such as ether, chloroform, olive oil, calomel, iodoform and phenol mixture. These larvae release toxins to destroy the host tissue $[16,17]$. Proteolytic enzymes released by the surrounding bacteria decompose the tissue and the larvae feed on this rotten tissue [18]. The infected tissue frequently releases a foul smelling discharge [16]. The necrotic ulcer around the teeth sockets and intense halitosis seen in the present case is suggestive of the destruction caused by toxins released by the larvae.

The role of antibiotics in oral myiasis is only supportive so as to prevent the development of infection secondary to the presence of necrotic area providing a nidus to the growth and multiplication of pathogenic microorganisms and should be discontinued when the wound has healed completely.

\section{CONCLUSION}

Myiasis could be prevented by maintaining good oral and personal hygiene, cleaning and covering the wounds and by educating the susceptible population about basic sanitation measures to be taken. Special care needs to be taken by the guardian/care-taker in medically compromised, dependent patients as the patients are unable to maintain their basic hygiene.

$$
* * * * * * * * *
$$

\section{Author Contributions}

Abdul Ahad G Khan - Conception and design, Acquisition of data, Analysis and interpretation of data, Drafting the article, Critical revision of the article, Final approval of the version to be published

Kanchan Milind Shah - Conception and design, Acquisition of data, Analysis and interpretation of data, Drafting the article, Final approval of the version to be published

\section{Guarantor}

The corresponding author is the guarantor of submission.

\section{Conflict of Interest}

Authors declare no conflict of interest.

\section{Copyright}

(C) Abdul Ahad G Khan et al. 2013; This article is distributed under the terms of Creative Commons Attribution 3.0 License which permits unrestricted use, distribution and reproduction in any means provided the original authors and original publisher are properly 
credited. (Please see www.ijcasereportsandimages.com /copyright-policy.php for more information.)

\section{REFERENCES}

1. Hope FW. On insects and their larvae occasionally found in human body. Royal Entomological Society Transactions 1840;2:236-71.

2. Zumpt F. Myiasis in man and animals in the old world. In: Zumpt F, editors. A Textbook for Physicians, Veterinarians and Zoologists. London: Butterworth and Co. Ltd 1965:109.

3. Shinohara EH, Martini MZ, Oliveira Neto HG, Takahashi A. Oral myiasis treated with ivermectin: case report. Braz Dent J 2004;15(1):79-81.

4. Bhatt AP, Jayakrishnan A. Oral myiasis: a case report. Int J Paediatr Dent 2000 Mar;10(1):67-70.

5. Prabhu SR, Praetorius F, Sena gupta SK. Myiasis. In: Prabhu SR, Wilson DF, Daftary DK, Johnson NW, editors. Oral Diseases in the Tropics. Oxford: Oxford University press 1992:302.

6. Abdo EN, Sette-Dias AC, Comunian CR, Dutra CE, Aguiar EG. Oral myiasis: a case report. Med Oral Patol Oral Cir Bucal 2006 Mar 1;11(2):E130-1.

7. Aguiar AM, Enwonwu CO, Pires FR. Noma (cancrum oris) associated with oral myiasis in an adult. Oral Dis 2003 May;9(3):158-9.

8. Laurence SM. Dipterous larvae infection. BMJ 1909;9:88.
9. Schneider TR, Cherubini K, Yurgel LS, Salum F, Figueiredo MA. Oral myiasis: a case report. J Oral Science 2007 Mar;49(1):85-8.

10. Bhoyar SC, Mishra YC. Oral myiasis caused by diptera in epileptic patient. J Indian Dent Assoc 1986 Dec;58(12):535-6.

11. Zeltser R, Lustmann J. Oral myiasis [corrected and issued with original paging in Int $\mathrm{J}$ Oral Maxillofac Surg 1988 Oct;17(5):288-9]. Int J Oral Maxillofac Surg 1989 Apr;18(2):288-9.

12. Bozzo L, Lima IA, De Almeida OP, Scully C. Oral myiasis caused by sarcophagidae in an extraction wound. Oral Surg Oral Med Oral Pathol 1992 Dec;74(6):733-5.

13. Grennan S. A case of oral myiasis. Br Dent J 1946 Apr 18;80:274.

14. Al-Ismaily M, Scully C. Oral myiasis: report of two cases. Int J Paed Dent 1995;5:177-9.

15. Sandhu DB, Bhaskar H. Textbook of Invertebrate Zoology. In: Sandhu DB, Bhaskar H, editors. Musca: The Housefly. New Delhi: Campus 2004:704-9.

16. Roszalina R, Rosalan R. Oral Myiasis: case report. Malaysian J Med Sci 2002 July;9(2):47-50.

17. Sood VP, Kakar PK, Wattal BL. Myiasis in otorhinolaryngology with entomological aspects. J Laryngol Otol 1976 Apr;90(4):393-9.

18. Lim ST. Oral myiasis--a review. Singapore Dent J 1974 May;13(2):33-4.
Access full text article on other devices

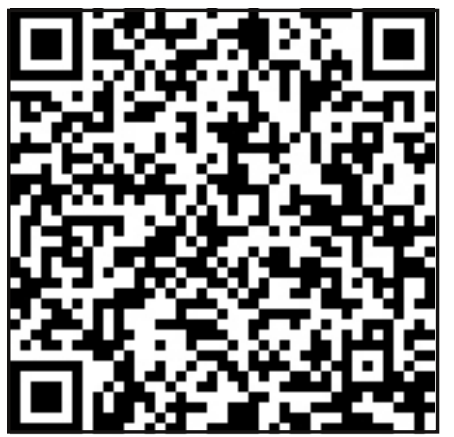

Access PDF of article on other devices

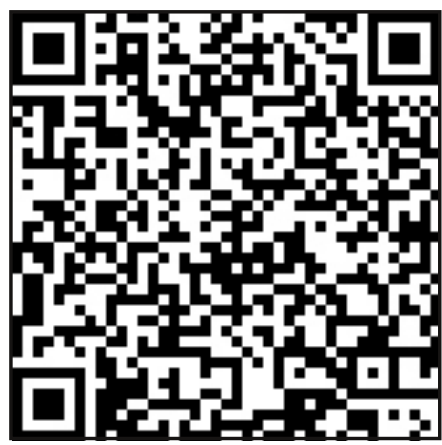

